\title{
O Desenvolvimento Humano em Porto Alegre: uma Análise das Dimensões Longevidade e Saúde, Educação, Renda e Trabalho em Regiões Selecionadas no Período 2000-2010
}

Human Development in Porto Alegre: an Analysis of the Dimensions Longevity and Health, Education, Income and Work in Selected Regions in the Period 2000-2010

\author{
Graciela Lobato dos Santos ${ }^{a}$ \\ Angélica Massuquettib \\ Karen Forneck Cardoso Michels ${ }^{c}$
}

\begin{abstract}
Resumo: O objetivo do estudo é analisar o desenvolvimento humano em Porto Alegre e em regiões selecionadas, no período de 2000 a 2010, nas dimensões longevidade e saúde, educação, e renda e trabalho. A metodologia empregada foi a análise do IDHM e de indicadores de desenvolvimento nessas dimensões. Os resultados revelaram que houve desenvolvimento humano, com destaque para longevidade e saúde. Houve disparidades na renda e muito baixo desenvolvimento em educação.
\end{abstract}

Palavras-chave: Desenvolvimento Humano; IDHM; Longevidade e Saúde; Educação; Renda e Trabalho; Porto Alegre.

Classificação JEL: O15

\begin{abstract}
The objective of the study is to analyze human development in Porto Alegre and in selected regions, from 2000 to 2010, in terms of longevity and health, education and income and work. The methodology used was the analysis of the IDHM and indicators of development in these dimensions. The results revealed that there was human development, with emphasis on longevity and health. There were disparities in income and very low development in education.
\end{abstract}

Keywords: Human Development; IDHM; Longevity and Health; Education; Income and Work; Porto Alegre.

\footnotetext{
${ }^{a}$ Graciela Lobato dos Santos. E-mail: gracilobato@yahoo.com.br

b Angélica Massuquetti. E-mail: angelicam@unisinos.br

${ }^{\mathrm{c}}$ Karen Forneck Cardoso Michels. E-mail: karenforneck@gmail.com
} 


\section{Introdução}

Este artigo tem como objetivo analisar o desenvolvimento humano em Porto Alegre e em regiões selecionadas do município, no período de 2000 a 2010, nas dimensões longevidade e saúde, educação e renda e trabalho. A principal motivação para o estudo desse tema reside no fato das pesquisas, geralmente, analisarem municípios específicos ou regiões metropolitanas. Destaca-se, contudo, que as desigualdades também podem ser observadas no espaço intramunicipal.

Porto Alegre, a capital do Rio Grande do Sul, é a sede da maior concentração urbana da Região Sul e o décimo município mais populoso do Brasil. O Índice de Desenvolvimento Humano Municipal (IDHM) de Porto Alegre é 0,805 (2010), o que coloca o município na faixa de muito alto desenvolvimento humano. A dimensão que mais contribuiu para o IDHM foi a renda $(0,867)$, seguida de longevidade $(0,857)$ e de educação $(0,702)$. Entre 2000 e 2010, a população cresceu em média 0,35\% e, nessa mesma década, a taxa de urbanização do município passou de $97,7 \%$ para 100\% (ATLAS BRASIL, 2019a). Apesar de possuir a melhor qualidade de vida entre os municípios brasileiros com mais de um milhão de habitantes, ocupando o primeiro lugar no IDHM, Porto Alegre possui desigualdades entre as suas 17 regiões no que se refere à longevidade, à educação e à renda. (ATLAS BRASIL, 2019a; OBSERVA POA, 2019a).

A análise do desenvolvimento humano de uma metrópole como Porto Alegre permite compreender as principais necessidades da população e o seu bem-estar, verificando quais políticas sociais podem ser aplicadas com o objetivo de melhorar a qualidade de vida da população nas suas diferentes regiões ${ }^{1}$. Neste estudo, optou-se por analisar o desenvolvimento humano das regiões com pior desempenho no IDHM, em 2010, que foram Nordeste (bairro Mário Quintana) (0,638), Ilhas (Ilha das Flores, da Pintada, do Pavão e Ilha dos Marinheiros) (0,659), Lomba do Pinheiro (bairros Agronomia e Lomba do Pinheiro) $(0,683)$ e Restinga (bairro Restinga) $(0,685)$. Essas regiões foram as únicas que apresentaram médio desenvolvimento humano no município de Porto Alegre.

Martins (2013), ao analisar os principais aspectos socioeconômicos da Região Metropolitana de Porto Alegre (RMPA), por exemplo, já havia observado que parte dos municípios da região, inclusive Porto Alegre, ainda apresentava desigualdades em algumas dimensões, como renda e saneamento. Assim, notou-se que o município está inserido em uma região que apresenta desigualdades socioeconômicas entre suas unidades municipais e, portanto, deve-se avaliar se o espaço local segue esse mesmo padrão. Martins, Germano e Rangel (2015) analisaram os municípios dessa mesma região e suas Unidades de Desenvolvimento Humano (UDHs). Segundo os autores, as desigualdades nas UDHs foram maiores do que aquelas apresentadas pelos municípios. Além disso, esse processo de descentralização permite verificar as regiões que precisam de mais atenção, como

\footnotetext{
${ }^{1}$ Por meio das parcerias entre o Programa das Nações Unidas para o Desenvolvimento (PNUD) e a Prefeitura de Porto Alegre, com participação da Fundação João Pinheiro e colaboração do Instituto Brasileiro de Geografia e Estatística (IBGE), entre outros, tem sido possível revelar as condições de vida da população do município e os fatores municipais que limitam o processo de expansão das liberdades. (ATLAS, 2008).
} 
intervenção de programas, políticas e ações específicas. A análise dos espaços intramunicipais, portanto, permite compreender a realidade municipal de forma mais ampla.

A perspectiva do desenvolvimento humano adotada neste estudo é pertinente ao ser humano e não apenas à renda, que deve ser apreendida como um meio e não o seu fim. Assim, as oportunidades e as capacidades dos indivíduos podem ser observadas por meio de diferentes dimensões, como as que são empregadas neste estudo: longevidade e saúde, educação e renda e trabalho.

Este artigo está dividido em cinco seções, considerando a Introdução. Na segunda seção discute-se o conceito multifacetado sobre desenvolvimento humano e são apresentados estudos empíricos sobre o desenvolvimento em Porto Alegre. Na terceira seção é descrita a metodologia adotada no estudo. Na quarta seção são expostos os resultados da pesquisa. Por fim, na quinta seção são apresentadas as conclusões do estudo.

\section{Desenvolvimento Humano: Aspectos Conceituais e Empíricos}

A abordagem do desenvolvimento humano surgiu para suprir as necessidades e as deficiências de outros enfoques, que eram direcionados para a análise da perspectiva do crescimento econômico (PNUD, 2019a). No ponto de vista do crescimento, como afirmou Nikiforos (2014), os lucros e os salários causariam flutuações de longo prazo, que afetariam o crescimento da economia e a distribuição de renda entre a população e, portanto, o bemestar. Além disso, para Kakwani e Son (2008), o crescimento não resultaria, automaticamente, em redução da pobreza. Identifica-se que essa perspectiva está centralizada na dimensão econômica.

O conceito de desenvolvimento humano, segundo Atlas Brasil (2019b), é empregado para avaliar as oportunidades e as capacidades dos indivíduos com base em três dimensões: vida longa e saudável, acesso ao conhecimento e padrão de vida digno. Sen (2010) destacou que o conceito das capacitações serve para definir o bem-estar da população. Ele abordou também a importância do funcionamento dos mercados e a qualidade de vida das pessoas, pois cada sociedade necessita de um tipo específico de mercadoria e essas mercadorias variam de pessoa para pessoa. As necessidades básicas estabelecem a quantidade e o tipo de mercadorias que irão utilizar e as capacitações permitem a percepção do desenvolvimento específico de bens e materiais. Outra contribuição de Sen (2012) foi definir que o desenvolvimento de um país se concretiza por meio das oportunidades que são proporcionadas à população, de poder realizar suas escolhas, de exercer sua própria cidadania.

Ao observar que o crescimento econômico não provocaria um aumento significativo na qualidade de vida das pessoas - e até mesmo poderia reforçar as desigualdades -, foi então que começou a busca por informações e indicadores que fossem capazes de proporcionar condições de mensurar melhorias no bem-estar da população. O Índice de 
Desenvolvimento Humano (IDH) ${ }^{2}$ é uma forma de verificar os avanços dos países e, antes da abordagem do desenvolvimento humano, o desempenho dos mesmos era medido por meio do Produto Interno Bruto (PIB) per capita, sendo que somente ponderava a dimensão econômica do desenvolvimento. Mesmo não abrangendo todas as dimensões do desenvolvimento, o IDH permite uma comparação do estágio socioeconômico dos países, bem como um conhecimento melhor da qualidade de vida da população (PNUD, 2019b).

No que se refere aos estudos empíricos acerca do desenvolvimento humano em Porto Alegre, Macedo (2019), por meio da revisão bibliográfica, destacou que isto depende essencialmente de um projeto coordenado pelo Estado e enfatizou a importância dos planos regionais e locais, conciliando estratégias para que possam promover a evolução das dimensões do desenvolvimento.

Costa (2019), por sua vez, analisou as desigualdades raciais no município de Porto Alegre, utilizando duas dimensões do desenvolvimento humano: saúde e educação, sendo que também foram abordadas as regiões do município. De acordo com a autora, nos anos 2000, os negros possuíam a mesma probabilidade de vida longa e saudável do que os brancos e em 1991, o coeficiente de mortalidade infantil foi similar entre os dois grupos étnicos. As desigualdades são visíveis quando se aborda o acesso ao conhecimento, já que o analfabetismo é maior entre os negros e as mulheres, que possuem um poder aquisitivo menor. Na escolaridade adulta, os negros possuem uma probabilidade menor de concluir o ensino fundamental. Sendo a educação essencial para o desenvolvimento de competências, capaz de proporcionar conhecimentos e melhora da autoestima, além de possibilitar uma melhor colocação no mercado de trabalho, observa-se, portanto, que ela desempenha papel fundamental para a redução da desigualdade social e racial.

Bassani (2019) teve o objetivo de apresentar uma descrição socioeconômica das Regiões do Orçamento Participativo (ROPs) de Porto Alegre, com a intenção de referir às "várias cidades" do município. A base de dados utilizada foi o Atlas do Desenvolvimento Humano da RMPA. Segundo a autora, mesmo que o município tenha apresentado indicadores elevados em relação às demais metrópoles brasileiras, ainda exibe muitas desigualdades regionais. Além disso, afirmou que a tentativa de parceria entre a administração pública e a comunidade não foi suficiente para suprir as carências da população. Por fim, a autora propõe que seria o momento de buscar alternativas por meio de uma nova regionalização que consiga captar melhor as condições de vida dos seus habitantes.

Por fim, o objetivo do estudo de Cavalcanti e Massuquetti (2012) foi analisar o desenvolvimento socioeconômico em Porto Alegre e em suas regiões, no período 19912007. A metodologia empregada foi a revisão bibliográfica e a análise do Índice de Desenvolvimento Socioeconômico (Idese) e do Índice de Pobreza Multidimensional (IPM). Os resultados revelaram que Porto Alegre obteve avanços no desenvolvimento. O

\footnotetext{
${ }^{2}$ O Relatório do Desenvolvimento Humano (RDH) foi publicado em 1990 e, em 2010, completou 20 anos, com novas metodologias que possibilitam uma análise mais completa para o cálculo do IDH (PNUD, 2019b).
} 
índice Renda apresentou um crescimento em todos os anos abordados e destacou-se entre os demais. Os piores resultados ficaram com Saneamento e Domicílio e Saúde, pois a qualidade do saneamento no município foi a pior dimensão em todos os anos estudados. Os autores concluíram que seria possível analisar outras capacitações, como segurança pública, utilização do sistema judiciário, infraestrutura das ruas, qualidades dos transportes etc. Essas capacitações poderiam abordar aspectos diferentes no desenvolvimento do município. Segundo os autores, o poder público do município deveria dar mais atenção às localidades onde há um baixo índice de desenvolvimento, buscando reduzir as desigualdades no município de Porto Alegre.

No Quadro 1 é apresentada uma síntese dos estudos analisados nesta seção.

\section{Quadro 1: Síntese dos Estudos Empíricos}

\begin{tabular}{|c|c|c|c|c|}
\hline Autores & Recorte & Período & Metodologia & Resultados \\
\hline $\begin{array}{l}\text { Macedo } \\
(2019)\end{array}$ & Porto Alegre & 2008 & $\begin{array}{c}\text { Revisão } \\
\text { bibliográfica }\end{array}$ & $\begin{array}{l}\text { Os projetos regionais e locais do } \\
\text { desenvolvimento devem ser } \\
\text { coordenados pelo Estado. }\end{array}$ \\
\hline Costa (2019) & $\begin{array}{l}\text { Porto Alegre e } \\
\text { regiões }\end{array}$ & $\begin{array}{l}1991- \\
2000\end{array}$ & $\begin{array}{l}\text { Indicadores } \\
\text { diversos }\end{array}$ & $\begin{array}{l}\text { Desigualdades raciais em razão do } \\
\text { acesso diferenciado à educação. }\end{array}$ \\
\hline $\begin{array}{l}\text { Bassani } \\
(2019)\end{array}$ & $\begin{array}{l}\text { ROPs de Porto } \\
\text { Alegre }\end{array}$ & $\begin{array}{l}1991- \\
2000\end{array}$ & $\begin{array}{c}\text { Indicadores } \\
\text { diversos }\end{array}$ & $\begin{array}{c}\text { O município ainda exibe muitas } \\
\text { desigualdades regionais. }\end{array}$ \\
\hline $\begin{array}{l}\text { Cavalcanti e } \\
\text { Massuquetti } \\
\quad(2012)\end{array}$ & Porto Alegre & $\begin{array}{l}1991- \\
2007\end{array}$ & Idese & $\begin{array}{l}\text { O índice Renda obteve um } \\
\text { crescimento em todos os anos. Os } \\
\text { piores resultados ficaram com } \\
\text { Saneamento e Domicílio e Saúde. }\end{array}$ \\
\hline
\end{tabular}

Fonte: Elaborado pelos autores.

Por meio da análise destas pesquisas, foi possível perceber que houve evolução no desenvolvimento de Porto Alegre. No entanto, o município ainda possui desigualdades persistentes entre suas diferentes regiões e apresenta carências em várias dimensões, como a educação.

\section{Métodos e Procedimentos}

O artigo emprega o modelo exploratório, apresentando, por meio de uma revisão da literatura, contribuições sobre o desenvolvimento humano nos aspectos conceituais e empíricos. A análise do desenvolvimento humano em Porto Alegre e em regiões selecionadas do município, em diferentes dimensões, é realizada pelas seguintes técnicas de coleta/análise de dados: (a) análise documental: os documentos são uma fonte de informações atuais ou históricas; e (b) descrição dos dados secundários. Ambos permitem comprovar esclarecimentos sobre determinado problema (SILVA; MENEZES, 2005; KLEIN et al., 2015). 


\section{1. Índice, Indicadores e Fonte de Dados}

O índice utilizado nesta pesquisa é o IDHM, calculado pelo Programa das Nações Unidas para o Desenvolvimento (PNUD), o Instituto de Pesquisa Econômica Aplicada (Ipea) e a Fundação João Pinheiro. Esse cálculo é obtido por meio dos Censos do Instituto Brasileiro de Geografia e Estatística (IBGE), nos anos 1991, 2000 e 2010. O IDHM foi criado em 1998 para ajustar o IDH em relação à realidade municipal das regiões metropolitanas. Seu principal objetivo é analisar a realidade dos municípios e os desafios enfrentados pelas regiões dentro das suas dimensões. O IDHM pode variar de 0 a 1: quanto mais próximo de 1, maior é o desenvolvimento humano nas dimensões abordadas (de 0 a 0,499, muito baixo; de 0,500 a 0,599, baixo; de 0,600 a 0,699, médio; de 0,700 a 0,799, alto; e de 0,800 a 1 , muito alto). (ATLAS BRASIL, 2019c).

O IDHM é importante porque valoriza as decisões e as ações das pessoas, não se limitando somente ao crescimento econômico, e estimula a realização de políticas públicas municipais para se obter uma melhoria na vida dos indivíduos. O IDHM aborda as mesmas dimensões do IDH, mas os indicadores que formam os índices são distintos (ATLAS BRASIL, 2019c): longevidade: expectativa de vida ao nascer; educação: fluxo escolar da população jovem e escolaridade da população adulta; e renda: renda per capita municipal.

Os índices e indicadores analisados neste estudo são apresentados no Quadro 2. O período de análise foi 2000/2010 e a fonte da pesquisa foi PNUD, Fundação João Pinheiro e Ipea. (ATLAS BRASIL, 2019a).

\section{Quadro 2: Índice, Indicadores e Fonte de Dados}

\begin{tabular}{|c|l|}
\hline \hline Índice/Subíndice/Indicador & \multicolumn{1}{|c|}{ Descrição } \\
\hline IDHM & Índice de Desenvolvimento Humano Municipal \\
\hline IDHM Longevidade & Índice de Desenvolvimento Humano Municipal - Longevidade \\
\hline IDHM Educação & Índice de Desenvolvimento Humano Municipal - Educação \\
\hline Escolaridade da população adulta & $\begin{array}{l}\text { Percentual de pessoas de } 18 \text { anos ou mais de idade com ensino } \\
\text { fundamental completo. }\end{array}$ \\
\hline Fluxo escolar da população jovem & $\begin{array}{l}\text { Percentual de crianças entre 5 e } 6 \text { anos frequentando a escola, percentual } \\
\text { de jovens entre 15 e 17 anos com ensino fundamental completo e } \\
\text { percentual de jovens entre 18 e 20 anos com ensino médio completo. }\end{array}$ \\
\hline IDHM Renda & Índice de Desenvolvimento Humano Municipal - Renda \\
\hline $\begin{array}{c}\text { Renda per capita } \\
\text { rendimentos do trabalho }\end{array}$ & $\begin{array}{l}\text { Indicador que ajuda medir o grau de desenvolvimento economico do país } \\
\text { ou região. }\end{array}$ \\
\hline $\begin{array}{c}\text { Rendimento médio dos ocupados } \\
-18 \text { anos ou mais }\end{array}$ & $\begin{array}{l}\text { Participação percentual das rendas provenientes do trabalho (principal e } \\
\text { outros) na renda total considerando apenas as pessoas que vivem em } \\
\text { domicílios particulares permanentes. }\end{array}$ \\
\hline $\begin{array}{c}\text { Média dos rendimentos de todos os trabalhos das pessoas ocupadas de 18 } \\
\text { anos ou mais de idade. }\end{array}$ \\
\hline $\begin{array}{c}\text { \% dos ocupados sem rendimento } \\
\text { de até 1s.m. - 18 anos ou mais }\end{array}$ & $\begin{array}{l}\text { Razão entre o número de pessoas de 18 anos ou mais de idade ocupadas e } \\
\text { sem rendimento do trabalho e o número total de pessoas ocupadas nessa } \\
\text { faixa etária. }\end{array}$ \\
\hline
\end{tabular}




\section{Quadro 2 (cont): Índice, Indicadores e Fonte de Dados}

\begin{tabular}{|c|c|}
\hline IÍndice/Subíndice/Indicador & Descrição \\
\hline Índice de Gini & $\begin{array}{l}\text { Mede o grau de desigualdade existente na distribuição de indivíduos } \\
\text { segundo a renda domiciliar per capita. Seu valor é } 0 \text { quando não há } \\
\text { desigualdade (a renda domiciliar per capita de todos os indivíduos tem o } \\
\text { mesmo valor) e tende a } 1 \text { medida que a desigualdade aumenta. }\end{array}$ \\
\hline $\begin{array}{l}\% \text { de empregados com carteira - } \\
18 \text { anos ou mais }\end{array}$ & $\begin{array}{l}\text { Razão entre o } \mathrm{n}^{\circ} \text {. de empregados de } 18 \text { anos ou mais com carteira de } \\
\text { trabalho assinada e o } \mathrm{n}^{\circ} \text {. total de pessoas ocupadas nessa faixa etária. }\end{array}$ \\
\hline $\begin{array}{c}\% \text { de empregados sem carteira - } \\
18 \text { anos ou mais }\end{array}$ & $\begin{array}{l}\text { Razão entre o } \mathrm{n}^{\circ} \text {. de empregados de } 18 \text { anos ou mais sem carteira de } \\
\text { trabalho assinada e o número total de pessoas ocupadas nessa faixa etária. }\end{array}$ \\
\hline $\begin{array}{l}\% \text { de trabalhadores do setor } \\
\text { público }-18 \text { anos ou mais }\end{array}$ & $\begin{array}{l}\text { Razão entre o } \mathrm{n}^{\circ} \text {. de trabalhadores do setor público de } 18 \text { anos ou mais } \\
\text { de idade e o } \mathrm{n}^{\circ} \text {. total de pessoas ocupadas nessa faixa etária. }\end{array}$ \\
\hline $\begin{array}{l}\% \text { de trabalhadores por conta } \\
\text { própria }-18 \text { anos ou mais }\end{array}$ & $\begin{array}{l}\text { Razão entre o } \mathrm{n}^{\circ} \text {. de trabalhadores por conta própria de } 18 \text { anos ou mais } \\
\text { de idade e o } \mathrm{n}^{\circ} \text {. total de pessoas ocupadas nessa faixa etária. }\end{array}$ \\
\hline $\begin{array}{c}\% \text { de empregadores }-18 \text { anos ou } \\
\text { mais }\end{array}$ & $\begin{array}{l}\text { Razão entre o } \mathrm{n}^{\circ} . \text { de empregados de } 18 \text { anos ou mais de idade e o } \\
\text { número total de pessoas ocupadas nessa faixa etária }\end{array}$ \\
\hline $\begin{array}{l}\% \text { dos ocupados com fundamental } \\
\text { completo - } 18 \text { anos ou mais }\end{array}$ & $\begin{array}{l}\text { Razão entre o }{ }^{\circ} \text {. de pessoas de } 18 \text { anos ou mais ocupadas que já } \\
\text { concluíram o ensino fundamental (regular seriado, regular não seriado, } \\
\text { EJA ou supletivo) e o } n^{\circ} \text {. total de pessoas ocupadas nessa faixa etária. }\end{array}$ \\
\hline $\begin{array}{l}\% \text { dos ocupados com médio } \\
\text { completo - } 18 \text { anos ou mais }\end{array}$ & $\begin{array}{l}\text { Razão entre o } \mathrm{n}^{\circ} \text {. de pessoas de } 18 \text { anos ou mais ocupadas que já } \\
\text { concluíram o ensino médio (regular seriado, regular não seriado, EJA ou } \\
\text { supletivo) e o } \mathrm{n}^{\circ} \text {. total de pessoas ocupadas nessa faixa etária. }\end{array}$ \\
\hline $\begin{array}{l}\% \text { dos ocupados com superior } \\
\text { completo - } 18 \text { anos ou mais }\end{array}$ & $\begin{array}{l}\text { Razão entre o }{ }^{\circ} \text {. de pessoas de } 18 \text { anos ou mais ocupadas e que já } \\
\text { concluíram a graduação do ensino superior e o } \mathrm{n}^{\circ} \text {. total de pessoas } \\
\text { ocupadas nessa faixa etária. }\end{array}$ \\
\hline
\end{tabular}

Fonte: Elaborado pelos autores com base em Atlas Brasil (2019f).

\subsection{Critério de Seleção das Regiões}

O município de Porto Alegre é dividido em 17 regiões, como se nota no Quadro 3. Estas fazem parte do Orçamento Participativo (OP) e das UDHs (PREFEITURA MUNICIPAL DE PORTO ALEGRE, 2019a).

\section{Quadro 3: Regiões de Porto Alegre}

\begin{tabular}{|c|c|}
\hline \hline Regiões & Bairros \\
\hline Centro & $\begin{array}{c}\text { Auxiliadora, Azenha, Bela Vista, Bom Fim, Centro Histórico, Cidade Baixa, } \\
\text { Farroupilha, Floresta, Independência, Jardim Botânico, Menino Deus, Moinhos de } \\
\text { Vento, MontSerrat, Petrópolis, Praia de Belas, Rio Branco, Santa Cecília, Santana }\end{array}$ \\
\hline Centro Sul & Camaquã, Campo Novo, Cavalhada, Nonoai, Teresópolis, Vila Nova \\
\hline Cristal & Cristal \\
\hline Cruzeiro & Medianeira e Santa Tereza \\
\hline Eixo Baltazar & Passo das Pedras, Rubem Berta \\
\hline Extremo Sul & Belém Novo, Chapéu do Sol, Lageado, Lami, Ponta Grossa \\
\hline Glória & Belém Velho, Cascata, Glória \\
\hline Humaitá / Navegantes & Anchieta, Farrapos, Humaitá, Navegantes, São Geraldo \\
\hline
\end{tabular}


Quadro 3 (cont.): Regiões de Porto Alegre

\begin{tabular}{|c|c|}
\hline Regiões & Bairros \\
\hline Ilhas & Arquipélago (Ilha das Flores, da Pintada, do Pavão e Ilha dos Marinheiros) \\
\hline Leste & $\begin{array}{l}\text { Bom Jesus, Chácaras das Pedras, Jardim Carvalho, Jardim do Salso, Jardim } \\
\text { Sabará, Morro Santana, Três Figueiras, Vila Jardim }\end{array}$ \\
\hline Lomba do Pinheiro & Agronomia, Lomba do Pinheiro \\
\hline Nordeste & Mario Quintana \\
\hline Noroeste & $\begin{array}{c}\text { Boa vista, Cristo Redentor, Higienópolis, Jardim Itu, Jardim Lindoia, Jardim São } \\
\text { Pedro, Passo da Areia, Santa Maria Goretti, São João, São Sebastião, Vila Floresta, } \\
\text { Vila Ipiranga }\end{array}$ \\
\hline Norte & Sarandi \\
\hline Partenon & Coronel Aparício Borges, Partenon, Santo Antônio, São José, Vila João Pessoa \\
\hline Restinga & Restinga \\
\hline Sul & $\begin{array}{c}\text { Espírito Santo, Guarujá, Hípica, Ipanema, Pedra Redonda, Serraria, Tristeza, Vila } \\
\text { Assunção, Vila Conceição }\end{array}$ \\
\hline
\end{tabular}

Fonte: Prefeitura Municipal de Porto Alegre (2019a)

Na Tabela 1 é possível observar a distribuição da população de Porto Alegre entre suas 17 regiões. Pode-se notar que, em 2010, a região Centro, que é formada por 18 bairros, possuía o maior número de habitantes, representando $19,64 \%$ da população total do município. Já região das Ilhas é a mais nova integrante desse grupo, pois foi inserida em 2008 e possui o menor número de habitantes, representando $0,59 \%$ da população de Porto Alegre.

Tabela 1: População de Porto Alegre e de suas regiões - 2010

\begin{tabular}{c|c|c}
\hline \hline Município e Regiões & População total (habitantes) & Participação no total (\%) \\
\hline Centro & 276.799 & 19,64 \\
\hline Centro Sul & 110.889 & 7,87 \\
\hline Cristal & 27.661 & 1,96 \\
\hline Cruzeiro & 65.408 & 4,64 \\
\hline Eixo Baltazar & 100.418 & 7,13 \\
\hline Extremo Sul & 34.873 & 2,47 \\
\hline Glória & 42.286 & 3,00 \\
\hline Humaitá / Navegantes & 43.689 & 3,10 \\
\hline Ilhas & $\mathbf{8 . 3 3 0}$ & $\mathbf{0 , 5 9}$ \\
\hline Leste & 114.309 & 8,11 \\
\hline Lomba do Pinheiro & $\mathbf{6 2 . 3 1 5}$ & $\mathbf{4 , 4 2}$ \\
\hline Nordeste & $\mathbf{3 7 . 2 3 4}$ & $\mathbf{2 , 6 4}$ \\
\hline Noroeste & 130.810 & 9,28 \\
\hline Norte & 91.366 & 6,48 \\
\hline Partenon & 118.923 & 8,44 \\
\hline Restinga & $\mathbf{6 0 . 7 2 9}$ & $\mathbf{4 , 3 1}$ \\
\hline Sul & 83.312 & 5,91 \\
\hline Porto Alegre & 1.409 .351 & 100,00 \\
\hline \hline
\end{tabular}

Fonte: Atlas Brasil (2019a). 
No Tabela 2, pode-se perceber que houve evolução no IDHM em todas as regiões e no município de Porto Alegre no período analisado. Em 2010, as regiões Centro e Noroeste obtiveram os melhores resultados nesse índice, 0,935 e 0,890, respectivamente, apresentando o nível muito alto de desenvolvimento. Além dessas regiões, Sul $(0,843)$ e Cristal $(0,809)$ também atingiram esse mesmo nível de desenvolvimento e todas ficaram acima de Porto Alegre, que obteve um índice de 0,805. Os piores desempenhos ficaram com as regiões Nordeste $(0,638)$, Ilhas $(0,659)$, Lomba do Pinheiro $(0,683)$ e Restinga $(0,685)$, que alcançaram, em 2010, apenas o nível médio do desenvolvimento.

Apesar da região Extremo Sul integrar o grupo de unidades territoriais com os piores desempenhos no IDHM do município, essa região atingiu o alto desenvolvimento, em 2010 e portanto, não foi incluída neste estudo.

Tabela 2: IDHM de Porto Alegre e de suas regiões - 2000/2010

\begin{tabular}{c|c|c}
\hline \hline \multirow{2}{*}{ Município e Regiões } & \multicolumn{2}{|c}{ IDHM } \\
\cline { 2 - 3 } & $\mathbf{2 0 0 0}$ & $\mathbf{2 0 1 0}$ \\
\hline Centro & 0,893 & 0,935 \\
\hline Centro Sul & 0,742 & 0,797 \\
\hline Cristal & 0,762 & 0,809 \\
\hline Cruzeiro & 0,671 & 0,747 \\
\hline Eixo Baltazar & 0,716 & 0,779 \\
\hline Extremo Sul & 0,629 & 0,714 \\
\hline Glória & 0,662 & 0,733 \\
\hline Humaitá / Navegantes & 0,693 & 0,765 \\
\hline Ilhas & $\mathbf{0 , 5 2 8}$ & $\mathbf{0 , 6 5 9}$ \\
\hline Leste & 0,713 & 0,777 \\
\hline Lomba do Pinheiro & $\mathbf{0 , 5 8 6}$ & $\mathbf{0 , 6 8 3}$ \\
\hline Nordeste & $\mathbf{0 , 5 1 1}$ & $\mathbf{0 , 6 3 8}$ \\
\hline Noroeste & 0,840 & 0,890 \\
\hline Norte & 0,648 & 0,729 \\
\hline Partenon & 0,698 & 0,764 \\
\hline Restinga & $\mathbf{0 , 5 9 5}$ & $\mathbf{0 , 6 8 5}$ \\
\hline Sul & 0,783 & 0,843 \\
\hline Porto Alegre & 0,744 & 0,805 \\
\hline
\end{tabular}

Fonte: Atlas Brasil (2019a) 
Figura 1: IDHM das Regiões do Município de Porto Alegre - 2010

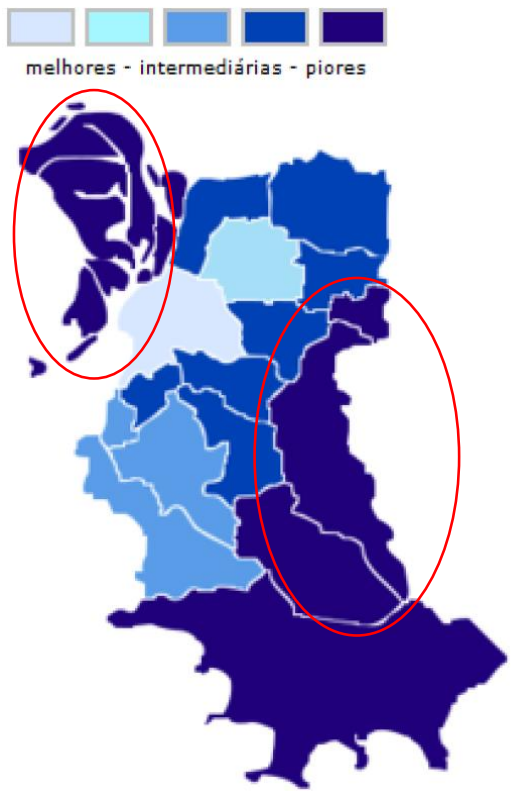

Fonte: Observa POA (2019b).

\section{Análise e Discussão dos Resultados}

\subsection{Desenvolvimento Humano}

No Gráfico 1, observa-se o desenvolvimento humano nas quatro regiões que apresentaram o menor desenvolvimento em Porto Alegre, considerando o IDHM. Apesar das regiões apresentarem o menor desenvolvimento no município de Porto Alegre, todas registraram evolução nas dimensões longevidade, educação e renda, refletindo no IDHM de forma positiva. O IDHM Longevidade passou da faixa de alto desenvolvimento para muito alto desenvolvimento em três regiões, dentre as quatro analisadas, destacando a melhora na qualidade de vida. A região das Ilhas foi a que obteve a maior evolução, em comparação às demais, passando de 0,746, em 2000, para 0,805, em 2010; seguida de Lomba do Pinheiro, que foi de 0,754, em 2000, para 0,806, em 2010, e Restinga, que registrou 0,755, em 2000, e 0,803, em 2010, igualando-se a Porto Alegre, em 2010, na faixa de muito alto desenvolvimento. A evolução do IDHM é oriunda de projetos e ações regionais e locais para a melhoria das três dimensões, como ressaltou Macedo (2019). 


\section{Gráfico 1: IDHM de Porto Alegre e de regiões selecionadas - 2000/2010}

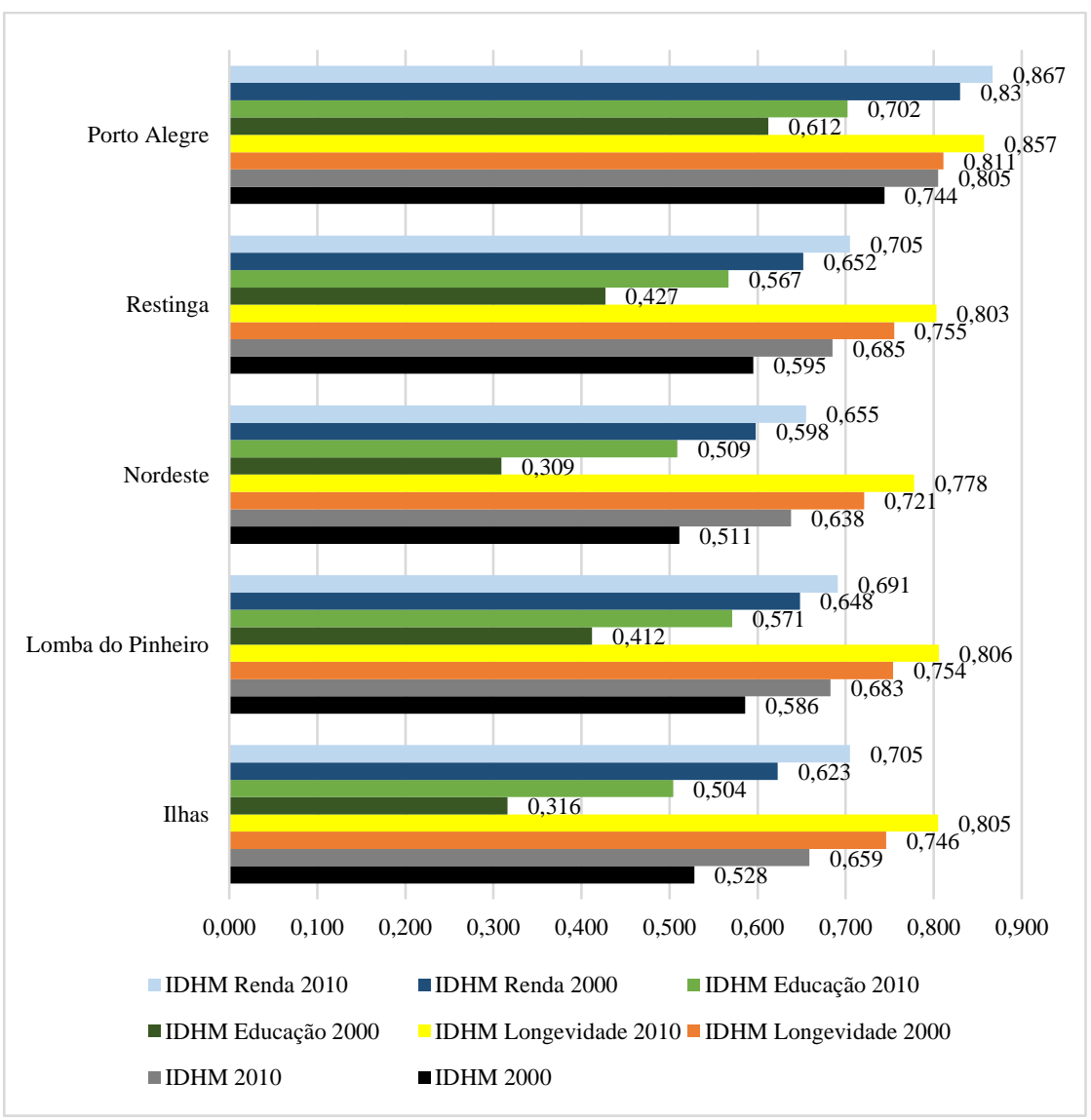

Fonte: Elaborado pelos autores a partir de Atlas Brasil (2019a).

O IDHM Educação apresenta a pior dimensão do índice nas regiões estudadas. Mesmo após a evolução, de 2000 para 2010, todas registram baixo desenvolvimento. Enquanto Porto Alegre apresentou 0,702 - alto desenvolvimento para o ano de 2010 -, Nordeste, região com maior evolução dentre as quatro, registrou 0,509, melhora de 0,2 em relação a 2000. Restinga e Lomba do Pinheiro apareceram com 0,567 e 0,571, respectivamente, destacando-se nessa dimensão com os melhores índices. Para o município de Porto Alegre, apesar de apresentar-se na faixa de alto desenvolvimento, a educação foi a pior dimensão, dentre longevidade e renda. Na seção 4.3 é possível analisar com mais propriedade as variáveis que interferem no cálculo do IDHM Educação e identificar, dentro dessa metodologia, a fragilidade dessa dimensão.

Referente ao IDHM Renda, as quatro regiões também apresentaram melhora, porém, nenhuma alcançou a faixa de muito alto desenvolvimento. Ilhas e Restinga registram evolução de mais de 0,053 pontos, passando para alto desenvolvimento, ambas com 0,705, 
em 2010. A região Nordeste apresentava, no ano de 2000, o pior índice de renda dentre as regiões analisadas, com 0,598 - baixo desenvolvimento, e registrou melhora significativa em 2010, com 0,655 - médio desenvolvimento. Lomba do Pinheiro evoluiu, porém não apresentou mudança, permanecendo na faixa de médio desenvolvimento. Comparando a dimensão renda das regiões com Porto Alegre, nota-se o município na faixa de muito alto desenvolvimento, bastante acima das regiões estudadas. Isto se deve, provavelmente, às regiões de mais alta renda - com maior PIB per capita - que o município possui e que elevam o valor calculado.

\subsection{Dimensão Longevidade e Saúde}

No Gráfico 2, pode-se observar o indicador que compõe o IDHM Longevidade e são apresentados outros indicadores na área de saúde. O IDHM Longevidade utiliza para o seu cálculo a esperança de vida ao nascer, que mostra o número médio de anos que uma pessoa nascida em determinado município viveria a partir do nascimento. Porto Alegre tem o indicador de esperança de vida ao nascer maior do que o Brasil, que em 2010 registrou 76,42 . Todas as regiões apresentaram evolução, sendo que o menor resultado é da região Nordeste, 71,67 anos, em 2010, e o melhor da Lomba do Pinheiro, 73,35 anos, nesse mesmo ano. Esse resultado favorável indica que há condições sociais, de saúde e de salubridade para a população em todas as faixas etárias. Em termos percentuais, em 10 anos, as regiões Ilhas e Nordeste evoluíram 5\%, Lomba do Pinheiro ampliou em 4,4\%, Restinga apresentou evolução de 4,1\% e Porto Alegre teve crescimento de 3,8\%.

\section{Gráfico 2: Indicador de Longevidade de Porto Alegre e de Regiões Selecionadas - 2000/2010}

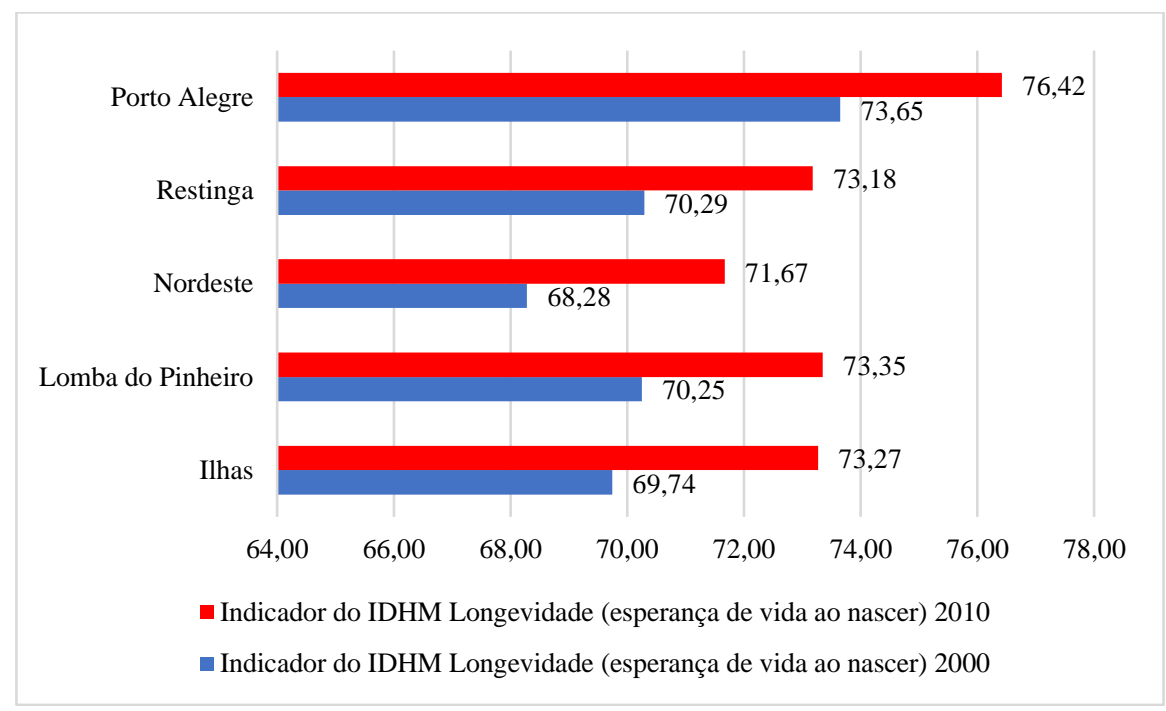

Fonte: Elaborado pelos autores a partir de Atlas Brasil (2019a). 
O indicador de mortalidade infantil apresentou uma evolução positiva e significativa para o município de Porto Alegre e também para as quatro regiões estudadas (Tabela 3). Em 2000, esse indicador oscilou entre 22,1 e 26,4 óbitos de crianças menores de um ano por mil nascidas vivias e, já em 2010, a pior situação foi registrada na região Nordeste, com 17,7 óbitos. As demais regiões estão entre 15,3 e 15,1. A evolução desse indicador é importante, pois reflete os níveis de saúde, desenvolvimento socioeconômico e condições de vida da população (DATASUS, 2019).

Tabela 3: Indicadores de Saúde de Porto Alegre e de Regiões Selecionadas 2000/2010

\begin{tabular}{c|c|c|c|c}
\hline \hline \multirow{2}{*}{ Municípios e Regiões } & \multicolumn{4}{|c}{ Indicadores de saúde } \\
\cline { 2 - 5 } & \multicolumn{2}{|c}{ Mortalidade infantil } & \multicolumn{1}{c}{ Mortalidade até 5 anos de idade } \\
\cline { 2 - 5 } & $\mathbf{2 0 0 0}$ & $\mathbf{2 0 1 0}$ & $\mathbf{2 0 0 0}$ & $\mathbf{2 0 1 0}$ \\
\hline Ilhas & $\mathbf{2 3 , 2}$ & $\mathbf{1 5 , 2}$ & $\mathbf{2 7 , 0 3}$ & $\mathbf{1 7 , 7 6}$ \\
\hline Lomba do Pinheiro & $\mathbf{2 2 , 2}$ & $\mathbf{1 5 , 1}$ & $\mathbf{2 5 , 8 1}$ & $\mathbf{1 7 , 6 2}$ \\
\hline Nordeste & $\mathbf{2 6 , 4}$ & 17,7 & 30,73 & $\mathbf{2 0 , 6 9}$ \\
\hline Restinga & $\mathbf{2 2 , 1}$ & $\mathbf{1 5 , 3}$ & $\mathbf{2 5 , 7 1}$ & $\mathbf{1 7 , 9 1}$ \\
\hline Porto Alegre & $\mathbf{1 6 , 0}$ & $\mathbf{1 1 , 6}$ & $\mathbf{1 8 , 6}$ & $\mathbf{1 3 , 1}$ \\
\hline \hline
\end{tabular}

Fonte: Elaborado pelos autores a partir de Atlas Brasil (2019a).

Por outro lado, o indicador de mortalidade para crianças até cinco anos de idade aumentou, em comparação à mortalidade infantil de crianças até um ano. A região Nordeste, apesar de registrar melhora, possui um indicador elevado de mortalidade, 50\% acima do que foi apresentado por Porto Alegre. Ilhas, Lomba do Pinheiro e Restinga também evoluíram positivamente, encontrando-se atualmente no mesmo patamar - entre 17,62 e 17,91 óbitos por mil nascidos vivos. No entanto, também estão piores do que Porto Alegre no ano de 2010.

\subsection{Dimensão Educação}

Na Tabela 4, podem-se observar os indicadores que compõe o IDHM Educação e a taxa de analfabetismo nas quatro regiões analisadas e no município de Porto Alegre nos anos 2000 e 2010. Ao analisar os dados do fluxo escolar dos jovens, observa-se que o maior percentual de jovens com ensino completo, conforme faixa etária, foram os de 11 a 13 anos com ensino fundamental completo. Em Porto Alegre, no ano de 2010, 86,8\% dos jovens estavam nessa condição e as regiões apresentam percentuais parecidos, destacando-se as Ilhas, com 94,9\%, nesse mesmo ano. Pode-se observar ainda que o percentual de concluintes do ensino fundamental diminuiu entre jovens de 15 a 17 anos, com máximo de 49,8\% no ano de 2010 na região das Ilhas, e mínimo de 33,0\% na região Nordeste. Referente ao ensino médio, os percentuais são preocupantes: o máximo de jovens entre 18 e 20 anos concluintes foi de $31,6 \%$, chegando a $19,0 \%$ na Restinga. O município de Porto Alegre registrou menos de 50\% dos jovens entre 18 e 20 anos com ensino médio completo. 


\section{Tabela 4: Indicadores de Educação de Porto Alegre e de Regiões Selecionadas - 2000/2010}

\begin{tabular}{|c|c|c|c|c|c|c|c|c|}
\hline \multirow{4}{*}{$\begin{array}{l}\text { Município e } \\
\text { Regiões }\end{array}$} & \multicolumn{8}{|c|}{ Indicadores do IDHM Educação } \\
\hline & \multicolumn{8}{|c|}{ Fluxo escolar dos jovens } \\
\hline & \multicolumn{2}{|c|}{$\begin{array}{c}\% \text { de } 5 \text { a } 6 \text { anos } \\
\text { na escola }\end{array}$} & \multicolumn{2}{|c|}{$\begin{array}{l}\% \text { de } 11 \text { a } 13 \text { anos } \\
\text { nos anos finais do } \\
\text { fundamental regular } \\
\text { seriado ou com } \\
\text { fundamental } \\
\text { completo }\end{array}$} & \multicolumn{2}{|c|}{$\begin{array}{l}\% \text { de } 15 \text { a } 17 \\
\text { anos com } \\
\text { fundamental } \\
\text { completo }\end{array}$} & \multicolumn{2}{|c|}{$\begin{array}{c}\% \text { de } 18 \text { a } 20 \\
\text { anos com } \\
\text { médio } \\
\text { completo }\end{array}$} \\
\hline & 2000 & 2010 & 2000 & 2010 & 2000 & 2010 & 2000 & 2010 \\
\hline Ilhas & 36,62 & 63,76 & 65,22 & 94,88 & 20,10 & 49,76 & 18,86 & 20,71 \\
\hline Lomba do Pinheiro & 40,58 & 60,60 & 67,83 & 88,57 & 43,05 & 49,59 & 17,7 & 31,58 \\
\hline Nordeste & 29,89 & 66,29 & 57,05 & 82,97 & 28,47 & 33,05 & 13,69 & 24,46 \\
\hline Restinga & 46,30 & 70,24 & 65,61 & 85,49 & 41,79 & 46,56 & 17,90 & 19,02 \\
\hline Porto Alegre & 60,84 & 77,71 & 75,46 & 86,84 & 57,96 & 59,30 & 44,25 & 48,18 \\
\hline \multirow{3}{*}{$\begin{array}{c}\text { Município e } \\
\text { Regiões }\end{array}$} & \multicolumn{4}{|c|}{ Indicadores do IDHM Educação } & \multicolumn{4}{|c|}{ Outro indicador de educação } \\
\hline & \multicolumn{4}{|c|}{$\begin{array}{l}\% \text { de } 18 \text { anos ou mais com } \\
\text { fundamental completo }\end{array}$} & \multicolumn{4}{|c|}{$\begin{array}{c}\text { Taxa de analfabetismo }-25 \text { anos } \\
\text { ou mais }\end{array}$} \\
\hline & \multicolumn{2}{|c|}{2000} & \multicolumn{2}{|c|}{2010} & \multicolumn{2}{|c|}{2000} & \multicolumn{2}{|c|}{2010} \\
\hline Ilhas & \multicolumn{2}{|c|}{25,45} & \multicolumn{2}{|c|}{38,95} & \multicolumn{2}{|c|}{13,91} & \multicolumn{2}{|c|}{6,17} \\
\hline Lomba do Pinheiro & \multicolumn{2}{|c|}{39,15} & \multicolumn{2}{|c|}{56,15} & \multicolumn{2}{|c|}{8,71} & \multicolumn{2}{|c|}{5,07} \\
\hline Nordeste & \multicolumn{2}{|c|}{28,33} & \multicolumn{2}{|c|}{49,42} & \multicolumn{2}{|c|}{9,61} & \multicolumn{2}{|c|}{6,23} \\
\hline Restinga & \multicolumn{2}{|c|}{42,37} & \multicolumn{2}{|c|}{59,46} & \multicolumn{2}{|c|}{7,57} & \multicolumn{2}{|c|}{3,84} \\
\hline Porto Alegre & \multicolumn{2}{|c|}{64,54} & \multicolumn{2}{|c|}{74,78} & \multicolumn{2}{|c|}{4,06} & 2,6 & \\
\hline
\end{tabular}

Fonte: Elaborado pelos autores a partir de Atlas Brasil (2019a).

Ao observar a escolaridade da população adulta - com 18 anos ou mais - com ensino fundamental completo, constatou-se que houve evolução entre 2000 e 2010 . A região Nordeste aumentou em 21,09 p.p., chegando a 49,4\%, em 2010. Apesar de não alcançar nem $50 \%$ da população, notou-se uma melhora na condição, quando comparado ao momento anterior, ano de 2000. Restinga e Lomba do Pinheiro registraram 59,5\% e 56,1\% de adultos com fundamental completo, respectivamente, no ano de 2010. A região das Ilhas foi a que apresentou o pior percentual, dentre as estudadas, com 39,0\%.

Por fim, para agregar à análise do indicador de educação, referente à taxa de analfabetismo de pessoas com 25 anos ou mais, Porto Alegre registrou uma taxa de 2,6\%, relativamente baixa quando comparada às regiões analisadas do próprio município. Nordeste evoluiu de 9,6\%, em 2000, para 6,2\%, em 2010, sendo a mais alta dentre as quatro investigadas. A região das Ilhas também registrou ganho, passando de 13,9\%, no ano de 2000, para 6,2\% em 2010. Há margem para melhora, como pode ser observado na Restinga, que em 2010 possuía uma taxa de analfabetismo de 3,8\%. A relação entre desigualdade e analfabetismo também foi abordada por Costa (2019), que concluiu que a educação é 
fundamental para o indivíduo, além de proporcionar conhecimentos e aprendizagem, também melhora a autoestima, torna-os cidadãos perante a sociedade e prepara-os para conquistar as vagas oferecidas no mercado de trabalho. A educação define a qualificação e o desenvolvimento do indivíduo, como ressaltou Chaves (2002).

A Rede Municipal de Ensino (RME) de Porto Alegre é constituída por 98 escolas e acolhe mais de 50 mil alunos da Educação Infantil, do Ensino Fundamental, do Médio, da Educação Profissional de Nível Técnico, da Educação de Jovens e Adultos (EJA) e da Educação Especial (PREFEITURA MUNICIPAL DE PORTO ALEGRE, 2019b). No Quadro 4, pode-se observar o número de escolas municipais e as divisões de ensino nas quatro regiões analisadas.

\section{Quadro 4: Escolas Municipais nas Regiões Selecionadas}

\begin{tabular}{|c|c|c|c|c|c|c|}
\hline Local & Bairros & Infantil & Fundamental & Médio & $\overline{\text { EJA }}$ & Total \\
\hline Ilhas & Arquipélago & $\begin{array}{l}\text { Emei da } \\
\text { Pintada }\end{array}$ & - & - & - & 1 \\
\hline $\begin{array}{l}\text { Lomba do } \\
\text { Pinheiro }\end{array}$ & $\begin{array}{l}\text { Agronomia e } \\
\text { Lomba do } \\
\text { Pinheiro }\end{array}$ & $\begin{array}{l}\text { Emei Maria M. } \\
\text { Fernandes; } \\
\text { Emei da Vima } \\
\text { Mapa II; Emei } \\
\text { da Vila Mapa } \\
\text { São Carlos } \\
\end{array}$ & $\begin{array}{l}\text { Emef Afonso G. } \\
\text { Lima; Emef Heitor } \\
\text { Vila Lobos; Emef } \\
\text { Saint Hilaire; Emef } \\
\text { São Pedro }\end{array}$ & - & - & 7 \\
\hline Nordeste & $\begin{array}{c}\text { Mario } \\
\text { Quintana }\end{array}$ & - & $\begin{array}{c}\text { Emef Dep Victor } \\
\text { Issler; Emef } \\
\text { Timbaúva; Emef } \\
\text { Wenceslau Fontoura }\end{array}$ & - & $\begin{array}{c}\text { Emef Dep } \\
\text { Victor Issler; } \\
\text { Emef } \\
\text { Wenceslau } \\
\text { Fontoura }\end{array}$ & 3 \\
\hline Restinga & Restinga & $\begin{array}{c}\text { Emei da Vila } \\
\text { Nova Restinga; } \\
\text { Emei Dom } \\
\text { Luiz de Nadal; } \\
\text { Emei Florência } \\
\text { Vurlod Sociais; } \\
\text { Emei Paulo } \\
\text { Freire }\end{array}$ & $\begin{array}{c}\text { Emef Tristão } \\
\text { Sucupira Viana; Emef } \\
\text { Dolores A. Caldas; } \\
\text { Emef Lidovino } \\
\text { Fanton; Emef Mario } \\
\text { Quintana; Emef N. } \\
\text { Sra. Do Carmo; Emef } \\
\text { Prof. Larry J. R. } \\
\text { Alves; Emef Sem. } \\
\text { Alberto Pasqualini; } \\
\text { Emef Ver Carlos P. } \\
\text { de Brum } \\
\end{array}$ & - & - & 12 \\
\hline $\begin{array}{l}\text { Porto } \\
\text { Alegre }\end{array}$ & 81 & 35 & 35 & 2 & 26 & 98 \\
\hline
\end{tabular}

Fonte: Elaborado pelos autores a partir de Prefeitura Municipal de Porto Alegre (2019b).

Ao observar o número de unidades de ensino das quatro regiões analisadas no município de Porto Alegre, identifica-se a falta de escolas de ensino médio municipal (o município possui apenas duas escolas de ensino médio) ${ }^{3}$. A região das Ilhas possui apenas

\footnotetext{
${ }^{3}$ Ressalta-se que o ensino médio é de competência do estado e não do município.
} 
uma escola de ensino infantil e isto se torna um aspecto negativo para a região, pois os jovens precisam se deslocar para outros bairros para dar continuidade aos estudos. Na região Lomba do Pinheiro, o bairro Agronomia não possui escolas e o bairro Lomba do Pinheiro possui sete escolas, sendo três de ensino infantil e quatro de ensino fundamental. A região Nordeste possui três escolas de ensino fundamental, sendo duas delas também com EJA. Por fim, a região da Restinga possui o maior número de escolas, sendo quatro de ensino infantil e oito de ensino fundamental, permitindo que as crianças e os jovens não tenham que se deslocar para outros bairros do município.

De acordo com Chaves (2002), quanto mais o trabalhador for qualificado, mais ele será remunerado. Além disso, seu nível educacional define sua qualificação. A educação, portanto, é um fator crucial para o crescimento do indivíduo e, consequentemente, de seus rendimentos. Além disso, há necessidade da educação e da experiência profissional para que os indivíduos possam ter oportunidades e minimizar as desigualdades, sendo fundamental a existência de políticas públicas.

\subsection{Dimensão Renda e Trabalho}

Na Tabela 5, pode-se verificar o indicador que compõe o IDHM Renda e outros indicadores relacionados à dimensão renda, nas quatro regiões analisadas e no município de Porto Alegre, nos anos 2000 e 2010. O IDHM Renda é composto somente pela renda per capita. Como forma de complementação, são abordados mais cinco indicadores referentes à dimensão.

Referente à renda per capita, a região das Ilhas se destacou com um aumento de $66,0 \%$, entre 2000 e 2010, o que provavelmente influenciou no bom desempenho na dimensão longevidade. A região Nordeste registrou evolução de 42,3\%, Restinga de 39,7\% e Lomba do Pinheiro de 30,6\%. Ao observar a renda per capita de Porto Alegre, nota-se uma discrepância significativa em comparação com as regiões de estudo que compõem o município. A vantagem de ter o cálculo por região é poder observar quais sofrem com a desigualdade de renda existente dentro do município. Porto Alegre possuía renda per capita de $\mathrm{R} \$ 1.758,27$ em 2010, e a região Nordeste, a mais carente, registrou $\mathrm{R} \$ 469,88$ nesse mesmo ano, ou seja, observam-se as desigualdades intramunicipais.

$\mathrm{O}$ indicador percentual da renda proveniente de rendimentos do trabalho mostra a participação dessa dimensão na renda total. Pode-se observar que Porto Alegre apresentou involução, passando de 71,5\% em 2000, para 69,8\% em 2010. Provavelmente, deve-se ao fato do percentual da renda proveniente de transferências governamentais ter aumentado. Duas regiões do município registraram melhora e as outras duas piora, nesse indicador. Todas, porém, estão acima de Porto Alegre, dado importante de ser destacado.

O rendimento médio dos ocupados - 18 anos ou mais melhorou em relação ao ano de 2000. A região Nordeste apresentou rendimento médio de $R \$ 806,72$, única região menor do que $\mathrm{R} \$ 1.000,00$, enquanto as demais estiveram acima, com máximo de $\mathrm{R} \$$ 1.240,55 - na região das Ilhas. As regiões analisadas são as mais carentes de Porto Alegre e, devido a isso, não refletem a média que o município possuía em 2010, R\$2.349,73, 
comprovando, novamente, a desigualdade dentro do município. Os rendimentos nas regiões e em Porto Alegre também foram observados por Chaves (2002), que já havia ressaltado que a educação é um dos principais fatores para o crescimento do indivíduo. As políticas públicas deveriam estar direcionadas para a qualificação e o conhecimento dos indivíduos das regiões com o menor desenvolvimento, já que eles serão mais bem remunerados se tiverem uma maior qualificação.

Tabela 5: Indicadores de Renda de Porto Alegre e de Regiões Selecionadas 2000/2010

\begin{tabular}{|c|c|c|c|c|c|c|}
\hline \multirow{3}{*}{$\begin{array}{l}\text { Município e } \\
\text { Regiões }\end{array}$} & \multicolumn{2}{|c|}{$\begin{array}{c}\text { Indicador do IDHM } \\
\text { Renda }\end{array}$} & \multicolumn{4}{|c|}{ Demais indicadores de renda } \\
\hline & \multicolumn{2}{|c|}{ Renda per capita } & \multicolumn{2}{|c|}{$\begin{array}{c}\% \text { da renda proveniente } \\
\text { de rendimentos do } \\
\text { trabalho }\end{array}$} & \multicolumn{2}{|c|}{$\begin{array}{c}\text { Rendimento médio dos } \\
\text { ocupados }-18 \text { anos ou } \\
\text { mais }\end{array}$} \\
\hline & 2000 & 2010 & 2000 & 2010 & 2000 & 2010 \\
\hline Ilhas & 387,03 & 642,58 & 80,6 & 84,59 & 847,65 & $1.240,55$ \\
\hline $\begin{array}{l}\text { Lomba do } \\
\text { Pinheiro }\end{array}$ & 452,27 & 590,83 & 77,98 & 79,09 & 953,3 & $1.001,47$ \\
\hline Nordeste & 330,08 & 469,88 & 82,32 & 76,77 & 751,69 & 806,72 \\
\hline Restinga & 461,15 & 644,32 & 76,09 & 74,15 & 978,67 & $1.035,86$ \\
\hline Porto Alegre & $1.399,50$ & $1.758,27$ & 71,52 & 69,78 & - & $2.349,73$ \\
\hline \multirow{3}{*}{$\begin{array}{l}\text { Município e } \\
\text { Regiões }\end{array}$} & \multicolumn{6}{|c|}{ Demais indicadores de renda } \\
\hline & \multicolumn{2}{|c|}{$\begin{array}{c}\% \text { dos ocupados sem } \\
\text { rendimento }-18 \text { anos } \\
\text { ou mais }\end{array}$} & \multicolumn{2}{|c|}{$\begin{array}{c}\% \text { dos ocupados com } \\
\text { rendimento de até } 1 \mathrm{~s} . \mathrm{m} \text {. } \\
-18 \text { anos ou mais }\end{array}$} & \multicolumn{2}{|c|}{ Índice de Gini } \\
\hline & 2000 & 2010 & 2000 & 2010 & 2000 & 2010 \\
\hline Ilhas & 5,82 & 1,11 & 50,56 & 25,86 & 0,56 & 0,57 \\
\hline $\begin{array}{c}\text { Lomba do } \\
\text { Pinheiro } \\
\end{array}$ & 0,91 & 0,81 & 33,52 & 11,84 & 0,49 & 0,42 \\
\hline Nordeste & 0,99 & 1,9 & 40,18 & 15,94 & 0,44 & 0,44 \\
\hline Restinga & 1,23 & 1,14 & 33,76 & 13,08 & 0,46 & 0,47 \\
\hline Porto Alegre & 1,47 & 1,13 & 20,22 & 8,66 & 0,60 & 0,60 \\
\hline
\end{tabular}

Fonte: Elaborado pelos autores a partir de Atlas Brasil (2019a).

O percentual dos ocupados sem rendimento - 18 anos ou mais variou entre as regiões. Nas Ilhas diminuiu de 5,8\% em 2000, para 1,1\% em 2010, resultado positivo e significativo. Lomba do Pinheiro e Restinga também apresentaram melhora, menos significativa, porém registrando evolução. Na região Nordeste observou-se piora, com aumento de 1,0\% em 2000, para 2,0\% em 2010. Dado positivo e que se percebeu evolução foi o percentual dos ocupados com rendimento de até um salário mínimo. Em todas as regiões do município houve queda, consequência provável de aumento dos rendimentos, significando melhora na qualidade de vida, conforme observado na dimensão longevidade. 
Porto Alegre possui o mesmo Índice de Gini que o estado do Rio Grande do Sul e o Brasil: 0,60. Esse valor é considerado elevado, ou acima da expectativa, pois quanto mais perto de 1 , maior a concentração de renda em poucas pessoas ${ }^{4}$. Nas regiões estudadas, $o$ índice de Gini é menor do que em Porto Alegre e, provavelmente, deve-se ao fato de serem regiões pobres, onde a maioria possui faixa de renda semelhante 5 .

Por fim, na Tabela 6, podem-se observar os indicadores de trabalho das quatro regiões analisadas, incluindo Porto Alegre, nos anos 2000 e 2010.

Referente aos dois primeiros indicadores, percentual de empregados com carteira e sem carteira com 18 anos ou mais, observa-se que houve aumento, no período analisado, no percentual de empregados com carteira assinada - 6,54 p.p. em Porto Alegre - e houve maior predominância destes, quando comparado ao \% de empregados sem carteira 13,1\%, em 2010, no município analisado. Esse cenário pode ter sido fortemente influenciado pelo incentivo dado aos empresários, por parte do Governo Federal, para regularização de seus funcionários.

O percentual de trabalhadores do setor público diminuiu de $8,2 \%$, em 2000, para 7,4\%, em 2010, em Porto Alegre. Dentre as regiões estudadas, somente as Ilhas obtiveram aumento, passando de $0,8 \%$ para 3,5\%, entre 2000 e 2010. Mesmo com o crescimento, é um percentual baixo, quando comparado com o município e com os demais indicadores analisados, sendo maior apenas que o percentual de empregadores com 18 anos ou mais.

O percentual de trabalhadores por conta própria nas regiões analisadas foi próximo ao de Porto Alegre, que registrou, em 2010, 21,6\%. É um dado relevante quando analisado pela ótica do empreendedorismo, pois são regiões carentes, que possuem renda menor do que as demais do município. Porém, com parte da população responsável por sua própria empresa. $\mathrm{O}$ indicador de percentual de empregadores vem para somar na análise sobre o perfil do trabalho. Pode-se observar que os trabalhadores por conta própria, na maior parte dos casos, não têm a necessidade de contratar funcionários, ou se os contratam não formalizam. Esse dado é visto principalmente nas regiões da Lomba do Pinheiro apresentou queda de $1,1 \%$ para $0,4 \%$; Nordeste - queda de $0,5 \%$ para $0,3 \%$; e Restinga queda de $1,5 \%$ para $0,8 \%$, entre 2000 e 2010 . A exceção foi a região das Ilhas, que evoluiu de $3,2 \%$ para $3,8 \%$, de 2000 para 2010.

Observa-se que o percentual de ocupados com fundamental completo é maior do que o percentual de ocupados com médio completo e significativamente maior do que ocupados com superior completo. Todas as regiões estudadas, inclusive o município como um todo, evoluíram no percentual de ocupados, em todas as esferas de ensino, fundamental, médio e superior, chegando a $80,8 \%$, no fundamental, $64,5 \%$ no médio e $27,8 \%$ no superior, no

\footnotetext{
${ }^{4}$ No Brasil, entre 1995 e 2005, segundo Kakwani e Son (2008), o crescimento no país, apesar de lento, beneficiou os pobres proporcionalmente mais do que os não-pobres. Contudo, de acordo com Hoffmann (2000), a análise do recorte nacional não permite a compreensão das características de cada região, que possibilitaria a formulação de ações e políticas para minimizar a desigualdade e permitir um incremento de renda das pessoas. Assim, os estudos de recortes territoriais devem ser estimulados.

${ }^{5}$ De acordo com Nikiforos (2014), a distribuição de renda é instável, pois quanto mais poder uma classe tem lucros ou salários, maior será seu potencial para apropriar-se do restante.
} 
ano de 2010, para Porto Alegre. O máximo de percentual dos ocupados com superior completo nas regiões estudadas foi de 7,3\%, bastante inferior a Porto Alegre. Esse indicador é a razão entre o número de pessoas de 18 anos ou mais de idade ocupadas que já concluíram o ensino fundamental e o número total de pessoas ocupadas nessa faixa etária. O que esse indicador mostra é que nas regiões analisadas poucas pessoas que estão ocupadas possuem o ensino superior completo, justificando o baixo percentual.

\section{Tabela 6: Indicadores de Trabalho de Porto Alegre e de Regiões Selecionadas - 2000/2010}

\begin{tabular}{|c|c|c|c|c|c|c|c|c|}
\hline \multirow{3}{*}{$\begin{array}{c}\text { Município e } \\
\text { Regiões }\end{array}$} & \multicolumn{8}{|c|}{ Demais indicadores de trabalho } \\
\hline & \multicolumn{2}{|c|}{$\begin{array}{c}\% \text { de empregados } \\
\text { com carteira }-18 \\
\text { anos ou mais }\end{array}$} & \multicolumn{2}{|c|}{$\begin{array}{c}\% \text { de empregados } \\
\text { sem carteira }-18 \\
\text { anos ou mais }\end{array}$} & \multicolumn{2}{|c|}{$\begin{array}{c}\% \text { de } \\
\text { trabalhadores do } \\
\text { setor público }-18 \\
\text { anos ou mais } \\
\end{array}$} & \multicolumn{2}{|c|}{$\begin{array}{c}\% \text { de } \\
\text { trabalhadores por } \\
\text { conta própria }-18 \\
\text { anos ou mais }\end{array}$} \\
\hline & 2000 & 2010 & 2000 & 2010 & 2000 & 2010 & 2000 & 2010 \\
\hline Ilhas & 37,73 & 41,59 & 18,81 & 21,77 & 0,82 & 3,5 & 34,14 & 28,2 \\
\hline Lomba do Pinheiro & 50,79 & 61,85 & 16,36 & 16,06 & 4,9 & 3,19 & 26,06 & 17,96 \\
\hline Nordeste & 51,36 & 59,81 & 20,89 & 19,7 & 2,14 & 2,04 & 24,29 & 16,67 \\
\hline Restinga & 50,57 & 61,77 & 19,39 & 14,49 & 5,79 & 3,62 & 21,67 & 18,21 \\
\hline Porto Alegre & 46,62 & 53,16 & 14,53 & 13,08 & 8,24 & 7,42 & 23,66 & 21,62 \\
\hline \multirow{3}{*}{$\begin{array}{c}\text { Município e } \\
\text { Regiões }\end{array}$} & \multicolumn{8}{|c|}{ Demais indicadores de trabalho } \\
\hline & \multicolumn{2}{|c|}{$\begin{array}{c}\% \text { de } \\
\text { empregadores - } 18 \\
\text { anos ou mais }\end{array}$} & \multicolumn{2}{|c|}{$\begin{array}{c}\% \text { dos ocupados } \\
\text { com fundamental } \\
\text { completo }-18 \\
\text { anos ou mais }\end{array}$} & \multicolumn{2}{|c|}{$\begin{array}{l}\text { \% dos ocupados } \\
\text { com médio } \\
\text { completo - } 18 \\
\text { anos ou mais }\end{array}$} & \multicolumn{2}{|c|}{$\begin{array}{c}\% \text { dos ocupados } \\
\text { com superior } \\
\text { completo }-18 \\
\text { anos ou mais }\end{array}$} \\
\hline & 2000 & 2010 & 2000 & 2010 & 2000 & 2010 & 2000 & 2010 \\
\hline Ilhas & 3,17 & 3,83 & 29,42 & 46,21 & 17,43 & 21,08 & 1,81 & 7,33 \\
\hline Lomba do Pinheiro & 1,08 & 0,39 & 45,62 & 64,07 & 20,72 & 35,24 & 2,05 & 4,52 \\
\hline Nordeste & 0,52 & 0,29 & 33,43 & 53,9 & 12,8 & 27 & 0,75 & 2,76 \\
\hline Restinga & 1,47 & 0,85 & 49,26 & 67,02 & 23,05 & 38,36 & 1,46 & 5,94 \\
\hline Porto Alegre & 5,53 & 3,76 & 72,26 & 80,76 & 56,07 & 64,53 & 21,24 & 27,81 \\
\hline
\end{tabular}

Fonte: Elaborado pelos autores a partir de Atlas Brasil (2019a).

Ao longo deste estudo, portanto, observou-se que houve desenvolvimento humano nas quatro regiões estudadas e em Porto Alegre. No que se refere à dimensão educação, apesar da evolução do índice no período de estudo, todas as regiões apresentaram muito baixo desenvolvimento em 2010. Em relação à renda, por fim, observou-se a desigualdade entre as regiões e das mesmas em relação ao município de Porto Alegre. 


\section{Conclusão}

Esta pesquisa teve como objetivo analisar o desenvolvimento humano em Porto Alegre e nas regiões Ilhas, Lomba do Pinheiro, Nordeste e Restinga, no período de 2000 a 2010, nas dimensões educação e renda e trabalho. Essas regiões foram as únicas que apresentaram médio desenvolvimento humano no município de Porto Alegre, em 2010. O município, apesar de ser uma das melhores capitais em qualidade de vida, apresenta disparidades no desenvolvimento humano de suas regiões.

Em relação à longevidade e saúde, as quatro regiões estudadas obtiveram crescimento no indicador de esperança de vida ao nascer, com destaque para Lomba do Pinheiro, que alcançou 73,35 anos em 2010. Porto Alegre, por sua vez, registrou, em 2010, 76,42 anos, alcançando uma colocação superior ao Brasil. Em relação à mortalidade infantil, a região Nordeste obteve o pior resultado, em 2010, com 17,7 óbitos, e no que se refere à mortalidade de crianças até 5 anos, essa mesma região também apresentou o pior desempenho.

Na dimensão educação, em relação ao fluxo escolar dos jovens, conforme a faixa etária, destacam-se os jovens de 11 a 13 anos com ensino fundamental completo, com 86,8\% e 94,9\% nessa condição, respectivamente, em Porto Alegre e nas Ilhas, em 2010. Ao observar a escolaridade da população adulta, constatou-se que houve evolução entre 2000 e 2010. Restinga registrou 59,5\% de adultos com fundamental completo, em 2010, enquanto a região das Ilhas foi a que apresentou o pior indicador, dentre as estudadas, com $38,9 \%$. Por fim, referente à taxa de analfabetismo de pessoas com 25 anos ou mais, Porto Alegre registrou 2,6\%, relativamente baixa quando comparada às regiões analisadas do próprio município: Nordeste apresentou $6,2 \%$ e nas Ilhas foi de 6,2\%.

No que se refere à dimensão renda, todas as regiões apresentaram evolução da renda per capita, com destaque para as Ilhas (aumento de 66,0\% no período). Contudo, ao considerar a renda per capita de Porto Alegre, nota-se uma disparidade significativa em comparação às regiões investigadas. $\mathrm{O}$ indicador percentual da renda proveniente de rendimentos do trabalho revelou que em todas as regiões houve maior participação desta fonte de renda quando comparadas à Porto Alegre. O Índice de Gini, nas regiões analisadas, em 2010, foi menor do que em Porto Alegre. A análise dos indicadores de trabalho permitiu constatar a desigualdade entre as regiões e das mesmas em relação à Porto Alegre.

Por fim, apesar da evolução do desenvolvimento humano em Porto Alegre e nas regiões investigadas, neste estudo, verificou-se que há disparidades entre as mesmas nas dimensões e a educação necessita de uma maior atenção do poder público. Sendo assim, como sugestão para pesquisas futuras, recomenda-se analisar a qualidade do ensino e a evolução dos gastos públicos em educação no município e regiões Ilhas, Lomba do Pinheiro, Nordeste e Restinga. Finalmente, também se recomenda a utilização Pesquisa Nacional por Amostra de Domicílios (PNAD) para a continuidade e a ampliação do período de estudo. 


\section{Referências}

ATLAS, do desenvolvimento humano da região metropolitana de Porto Alegre. Porto Alegre: Prefeitura Municipal/Secretaria de Coordenação Política e Governança Local; Metroplan; PNUD; Fundação João Pinheiro. 2008.

ATLAS, do Desenvolvimento Humano no Brasil. Consulta. Atlas Brasil. 2019a. Disponível em: http://www.atlasbrasil.org.br/2013/pt/consulta/. Acesso em: 10 jan. 2019. ATLAS, do Desenvolvimento Humano no Brasil. Desenvolvimento Humano. Atlas Brasil. 2019b. Disponível em: http://www.atlasbrasil.org.br/2013/pt/o_atlas/desenvolvimento_humano/. Acesso em: 10 jan. 2019.

ATLAS, do Desenvolvimento Humano no Brasil. O IDHM. Atlas Brasil. 2019c.

Disponível em: http://www.atlasbrasil.org.br/2013/pt/o_atlas/desenvolvimento_humano/. Acesso em: 10 jan. 2019.

BASSANI, V. S. Porto Alegre desigual: retratos de uma metrópole. Disponível em: http://lproweb.procempa.com.br/pmpa/prefpoa/observatorio/usu_doc/porto_alegre_desigu al.pdf. Acesso em: 20 jan. 2019.

CAVALCANTI, J. S.; MASSUQUETTI, A. A evolução recente do desenvolvimento em Porto Alegre. Diálogo, 21: p. 125-150. 2012.

CHAVES, A. L. L. Determinação dos rendimentos na Região Metropolitana de Porto Alegre: uma verificação empírica da Teoria do Capital Humano. Ensaios FEE, 23: p, 399-420. 2002.

COSTA, B. M. Aspectos da desigualdade racial em Porto Alegre. Disponível em: http://lproweb.procempa.com.br/pmpa/prefpoa/observatorio/usu_doc/texto_raca_etnia_3. pdf. Acesso em: 20 jan. 2019.

DATASUS. Disponível em: http://tabnet.datasus.gov.br/cgi/idb2000/fqc01.htm. Acesso em: 10 jan. 2019.

HOFFMANN, R. Mensuração da desigualdade e da pobreza. In: HENRIQUES, R. (Org.). Desigualdade e pobreza no Brasil. Rio de Janeiro, IPEA, 2000.

KARWANI, N.; SON, H. H. Poverty equivalent growth rate. The Review of Income and Wealth, 54: 4, p. 643-655. 2008. DOI: https://doi.org/10.1111/j.1475-4991.2008.00293.x KLEIN, A.; SILVA, L.; MACHADO, L.; AZEVEDO, D. Metodologia de pesquisa em administração: uma abordagem prática. São Paulo: Atlas. 2015. 
MACEDO, C. E. O desenvolvimento que buscamos para Porto Alegre. Disponível em: http://lproweb.procempa.com.br/pmpa/prefpoa/observatorio/usu_doc/comudes2.pdf. Acesso em: 20 jan. 2019.

MARTINS, C. M. R. Caracterização da Região Metropolitana de Porto Alegre. Textos para Discussão, FEE, 112. 2013.

MARTINS, C. M. R.; GERMANO, L. R. R. G. B. N.; RANGEL, R. R. Unidades de Desenvolvimento Humano da Região Metropolitana de Porto Alegre. Disponível em: http://lproweb.procempa.com.br/pmpa/prefpoa/observatorio/usu_doc/unidades_de_desen volvimento_humano_da_regiao_metropolitana_de_porto_alegre_2015.docx. Acesso em: 20 jan. 2019.

NIKIFOROS, M. Distribution-led Growth in the Long Run. Working Paper, n. 814. 2014. DOI: https://doi.org/10.2139/ssrn.2491094

OBSERVATÓRIO da Cidade de Porto Alegre (OBSERVA POA). Análises comparativas intraurbanas. $2019 \mathrm{~b}$.

Disponível em: http://portoalegreemanalise.procempa.com.br/?analises=2_114_0. Acesso em: 20 fev. 2019.

OBSERVATÓRIO da Cidade de Porto Alegre (OBSERVA POA). Porto Alegre. 2019a. Disponível em: http://portoalegreemanalise.procempa.com.br. Acesso em: 20 jan. 2019.

PREFEITURA Municipal de Porto Alegre. Plano Municipal de Educação 2015-2025. 2015. Disponível em:

http://websmed.portoalegre.rs.gov.br/escolas/eventos/congresso/final/plano_vf_1.pdf. Acesso em: 20 jan. 2019.

PREFEITURA Municipal de Porto Alegre. Regiões do Orçamento Participativo. 2019a.

Disponível em: http://www2.portoalegre.rs.gov.br/op/default.php?reg=2\&p_secao=5. Acesso em: 20 jan. 2019.

PREFEITURA Municipal de Porto Alegre. Secretaria Municipal de Educação. 2019b. Disponível em: http://www2.portoalegre.rs.gov.br/smed/default.php?p_secao=242. Acesso em: 10 jan. 2019.

PROGRAMA das Nações Unidas para o Desenvolvimento (PNUD). O que é desenvolvimento humano. 2019 ${ }^{\text {a }}$. Disponível em:

http://www.pnud.org.br/IDH/DesenvolvimentoHumano.aspx?indiceAccordion=0\&li=li_ DH. Acesso em: 22 jan. 2019.

PROGRAMA das Nações Unidas para o Desenvolvimento (PNUD). O que é o IDH. 2019b. 
Disponível em: http://www.pnud.org.br/IDH/IDH.aspx?indiceAccordion=0\&li=li_IDH. Acesso em: 22 jan. 2019.

SEN, A. K. Desenvolvimento como liberdade. São Paulo: Companhia de Letras. 2010.

SEN, A. K. Mercados, justiça e liberdade. 2012.

Disponível em: http://veja.abril.com.br/blog/ricardo-setti/vasto-mundo/entrevistaimperdivel-com-o-nobel-de-economia-amartya-sen-ele-fala-sobre-china-india-brasil-ediz-que-a-crise-na-europa-se-resolve-com-enfase-no-crescimento/. Acesso em: 12 jan. 2019.

SILVA, E. L. da; MENEZES, E. M. Metodologia da pesquisa e elaboração de dissertação. 4. ed. rev. ampl. Florianópolis: UFSC. 2005. 